\title{
Subclinical Peroneal Neuropathy: A Common, Unrecog- nized, and Preventable Finding Associated With a Recent History of Falling in Hospitalized Patients
}

Louis H. Poppler, MD, MSCI ${ }^{1}$

Andrew P. Groves, $M D^{2}$

Gina Sacks, $M D^{2}$

Anchal Bansal, BS 2

Kristen M. Davidge, MD, MSc ${ }^{3}$

Jenifer A. Sledge, $P b D^{4}$

Heidi Tymkew, DPT, MHS

Yan Yan, MD, PbD

Jessica M. Hasak, RN, MPH

Patricia Potter, PbD

Susan E. Mackinnon, $M D^{1}$

'Division of Plastic \& Reconstructive Surgery, Washington University in St Louis School of Medicine, St Louis, Missouri

${ }^{2}$ Washington University in St Louis School of Medicine, St Louis, Missouri

${ }^{3}$ The Hospital for Sick Children, Toronto, Ontario, Canada

${ }^{4}$ BJC HealthCare, St Louis, Missouri

${ }^{5}$ Department of Surgery, Washington University in St Louis School of Medicine, St Louis, Missouri

Conflicts of interest: authors report none.

\section{CORRESPONDING AUTHOR}

Susan E. Mackinnon, MD

Division of Plastic \& Reconstructive Surgery

Washington University in St Louis School of Medicine

660 S Euclid Ave; Campus Box 8238

St Louis, MO 63110

mackinnon@wudosis.wustl.edu

\begin{abstract}
PURPOSE Identification of modifiable risk factors for falling is paramount in reducing the incidence and morbidity of falling. Peroneal neuropathy with an overt foot drop is a known risk factor for falling, but research into subclinical peroneal neuropathy (SCPN) resulting from compression at the fibular head is lacking. The purpose of our study was to determine the prevalence of SCPN in hospitalized patients and establish whether it is associated with a recent history of falling.
\end{abstract}

METHODS We conducted a cross-sectional study of 100 medical inpatients at a large academic tertiary care hospital in St Louis, Missouri. General medical inpatients deemed at moderate to high risk for falling were enrolled in the summer of 2013. Patients were examined for findings that suggest peroneal neuropathy, fall risk, and a history of falling. Multivariate logistic regression was used to correlate SCPN with fall risk and a history of falls in the past year.

RESULTS The mean patient age was 53 years (SD $=13$ years), and 59 patients $(59 \%)$ were female. Thirty-one patients had examination findings consistent with SCPN. After accounting for various confounding variables within a multivariate logistic regression model, patients with SCPN were 4.7 times $(95 \% \mathrm{Cl}$, 1.4-15.9) more likely to report having fallen 1 or more times in the past year.

CONCLUSIONS Subclinical peroneal neuropathy is common in medical inpatients and is associated with a recent history of falling. Preventing or identifying SCPN in hospitalized patients provides an opportunity to modify activity and therapy, potentially reducing risk.

Ann Fam Med 2016;14:526-533. doi: 10.1370/afm.1973.

\section{INTRODUCTION}

A pproximately 1 million hospitalized patients in the United States fall annually, causing significant morbidity ${ }^{1,2}$ and leading to longterm care facility admission for many elderly patients. ${ }^{3}$ Although foot drop associated with overt peroneal neuropathy is a known risk factor for falls, subclinical peroneal neuropathy (SCPN) is not. ${ }^{4-6}$ Identification of modifiable risk factors for falling is paramount to reducing fall incidence. SCPN is a preventable and treatable condition that may place hospitalized or recently hospitalized patients at increased risk for falling.

Overt peroneal neuropathy is characterized by inability to flex the foot in a dorsal direction as a result of muscle weakness and is associated with the characteristic steppage gate commonly referred to as foot drop. In contrast, SCPN caused by compression at the fibular head is subtle and may be easily missed during routine physical examination. ${ }^{5,7,8}$ Subjective symptoms of SCPN include discomfort at the lateral knee, pain along the anterolateral leg (shin splints), sensory loss on the dorsal foot, or a propensity to stub the toe. ${ }^{5,9}$ Unlike overt peroneal neuropathy, patients with SCPN exhibit mild weakness of dorsiflexion/eversion that may be missed on standard strength examination. Although not done routinely, screening for peroneal neuropathy consists of a focused patient history and a simple physical examination, 
including the Tinel test and strength testing of dorsiflexion, eversion, and plantar flexion..$^{10,11}$ Collectively, these tests can be performed in less than 1 minute.

The prevalence of SCPN caused by compression at the fibular head and its association with falling has not previously been studied. We hypothesize SCPN involves weakness of dorsiflexion not severe enough to cause foot drop that predisposes patients to experience frequent trips and falls. The purpose of this study is to determine the prevalence of SCPN in hospitalized adults and examine its association with falling.

\section{METHODS}

Our cross-sectional study was designed to evaluate the prevalence of SCPN in hospitalized patients and its association with falls. Peroneal neuropathy was evaluated based on physical examination by 4 trained research personnel during each patient's hospital stay. Falls were determined by patients' self-report of having 1 or more falls during the past year. We also evaluated a secondary association between SCPN and a high score for a risk of falling on the Activities-specific Balance Confidence Scale (ABC) Scale. ${ }^{12}$

\section{Patients}

The study population consisted of adult inpatients at a single large academic hospital on 4 general medicine wards. These floors did not include patients admitted to the oncology, cardiology, neurology, psychiatry, physical medicine and rehabilitation, or surgery services. All consecutively admitted patients aged 18 to 70 years, who were English speaking, able to follow verbal commands, ambulatory, and deemed at moderate or high risk for falling, were eligible for inclusion.

Risk of falling was assessed using the Johns Hopkins Fall Risk Assessment score ${ }^{13,14}$; a score of less than 6 is considered low risk, 6 to 13 is considered moderate risk, and greater than 13 is considered high risk. ${ }^{13-15}$ Patients were eligible for inclusion in this study if their risk score on admission was 6 or greater. Patients were excluded if they had a diagnosis of dementia, could not clearly remember the past year, could not sit on the edge of the bed, or were unable to participate in a verbal evaluation.

All patients signed an informed consent document. This study was reviewed and approved by the Human Research Protection Office at Washington University School of Medicine, St Louis, Missouri (\#201301032).

\section{Patient Evaluation}

To minimize measurement bias, physical examination was performed by a minimum of 3 independent examiners blinded to each other's results before taking a patient's history and explaining the importance of the tests to patients. For consistency, all tests were performed with the patients sitting upright on the edge of the bed or in a bedside chair.

\section{Physical Examination}

Peroneal nerve entrapment caused by compression at the fibular head was assessed by asking about pain at the fibular head, by using the Tinel sign, ${ }_{1}^{16,17}$ and by manual muscle force testing. Highly reliable $(\kappa=0.79),{ }_{1}^{18}$ the Tinel test was deemed positive if 2 or more examiners obtained a positive result. This test, which is moderately sensitive and highly specific for nerve entrapment, ${ }^{8,19}$ involves provoking the nerve at known points of entrapment, looking for tingling or pain radiating into the dorsal foot. Findings are either present or absent. For the common peroneal nerve, the entrapment site is at the fibular neck.

Manual muscle force testing was performed for ankle dorsiflexion and eversion using the Medical Research Council (MRC) grading system. ${ }^{20}$ MRC strength for each movement (dorsiflexion, eversion, inversion, plantar flexion) was determined by taking the most common score (usually MRC 4 or 5). A pilot study indicated that interrater agreement was strong among the 3 examiners, with an intraclass correlation coefficient (ICC) of 0.85 (95\% CI, 0.73-0.92).

We also tested strength of ankle plantar flexion and inversion to distinguish peroneal neuropathy from lumbar radiculopathy or generalized weakness. Patients were then categorized as having no weakness, peroneal weakness, or global weakness. Peroneal weakness was defined as weakness (MRC grade $<5$ ) in muscles innervated by the peroneal nerve (dorsiflexion and ankle eversion). If patients were weak in muscles powered by both the peroneal and tibial nerve, they were classified as having both peroneal and global weakness.

SCPN caused by compression at the fibular head was determined by the number of examination findings (pain over the fibular head, positive Tinel sign, peroneal weakness); patients with 2 or more findings were considered to have SCPN. Overt peroneal neuropathy (foot drop) was diagnosed if patients exhibited a dorsiflexion MRC strength grade of 3 or less.

\section{History}

Findings on examination were not explained to patients before taking their history to minimize the potential for recall bias. The following information was obtained from patient report and chart review: a history of falling 1 or more times in the past year, frequent tripping or near falls in the past year, vertigo, dizziness, vestibular disorders, other balance problems, cardiovascular disease, stroke, diabetes mellitus, neuropathy, 
heavy alcohol use (more than 3 drinks at a sitting at least once weekly), recent major weight loss (more than 15 pounds in 3 months), and knee or hip replacement surgery. All patients also completed the ABC Scale, an instrument that assesses a patient's perceived risk of falling during daily activity. ${ }^{12}$ Each item is scored from 0 to 100 . This scale has been validated in communitydwelling adults, and a score of 67.0 or less indicates an increased risk for falling. ${ }^{21}$

\section{Statistical Analysis}

Descriptive statistics and differences were computed for patients with and without findings of SCPN. Mean with standard deviation or median with range are presented for normally or nonnormally distributed data, respectively. The $\chi^{2}$ test or Kruskal-Wallis $\mathrm{H}$ test were used to compare proportions or group distributions, respectively. Univariate logistic regression was used to test the relationships between number of physical examination findings suggesting SCPN and self-reported history of falling or being at high risk for falling on the $\mathrm{ABC}$ Scale (score of less than 67.0). The effects of potential confounders on these associations were tested using multivariate logistic regression and a forward entry approach. ${ }^{22}$ The following potential confounders were selected a priori based on literature review: age, history of stroke, diabetes, osteoarthritis, vertigo, dizziness, balance disorder, poor vision/blindness, heavy alcohol use, recent major weight loss, peripheral neuropathy, and generalized (global) weakness. These variables were sequentially added to the model based on their magnitude of effect on the $\beta$ coefficients of either 1 or 2 or more findings on physical examination suggestive of peroneal neuropathy. This process was repeated until all potential confounders that changed the $\beta$ coefficient by more than $10 \%$ had been added to the model. All analyses were performed in conjunction with an independent biostatistician using an $\alpha$ of .05 and SAS version 13.2 (SAS Inc). All associations are presented as an odds ratio and $95 \%$ confidence intervals.

\section{RESULTS}

\section{Patient Characteristics}

A total of 246 inpatients were screened during the 1-month study period. Of these, 126 met eligibility criteria and were approached for enrollment. Twentysix patients declined to participate, leaving 100 patients in the final cohort. No patients withdrew from the study, and there were no missing data (Figure 1). The median age was 57 years (interquartile range [IQR], 45-64 years); 59 patients were female. The median hospital stay at the time of assessment was 2 days (range 1-7 days). The median Johns Hopkins Fall Risk score for the entire cohort was 7 (range 6-19), consistent with this group of patients being at moderate risk of falling while an inpatient. Eight patients had a Johns Hopkins Fall Risk Score of greater than 13, indicating high risk for falling while an inpatient. No patient fell while admitted to the hospital.

\section{Prevalence of SCPN}

Thirty-one patients had 2 or more positive findings on physical examination, meeting the definition for SCPN. Sixty-seven patients had at least 1 positive finding. No patients showed overt peroneal neuropathy. Patients with SCPN were significantly more likely to have vertigo, dizziness, or a balance disorder and had a significantly greater median Johns Hopkins Fall Risk score (Table 1).

Pain at the fibular head was the most common physical finding, affecting 48 patients. Twenty-two patients exhibited a positive Tinel sign. Among

\section{Figure 1. Study design and patient enrollment.}

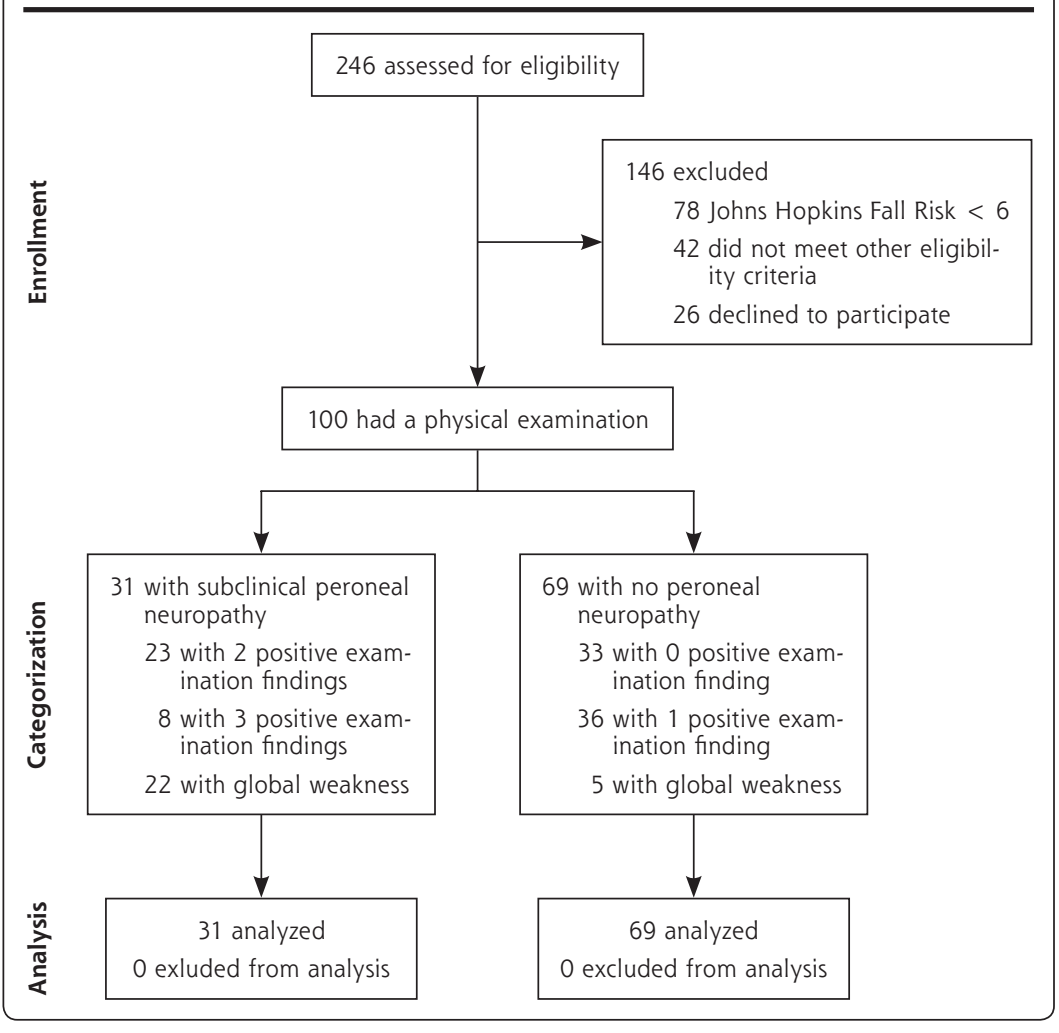


patients with 2 or more findings of SCPN, weakness of muscles innervated by the peroneal nerve was the most common finding, affecting 27 of 31 patients (87\%).

\section{Prevalence of Falling and Elevated Perceived Fall Risk}

Forty-eight patients self-reported falling at least once in the past year. No falls resulted in significant injury. Thirty-nine patients reported frequent tripping or near falls in the past year, which was significantly correlated with falling $\left(\chi^{2}{ }_{1}=6.642, P<.01\right)$. Median ABC Scale score was 69.4 (IQR, 46.3-90.6). Forty-nine patients had an ABC Scale score of less than 67.0, suggesting elevated fall risk. Within this patient sample at this cutoff, the ABC Scale score and self-reported fall his-

\section{Table 1. Characteristics of 100 Consecutively Admitted Medial Inpatients Aged 70 Years or Younger Deemed at Moderate to High Risk of Falling}

\begin{tabular}{|c|c|c|c|c|}
\hline \multirow[b]{2}{*}{ Characteristic } & \multirow[b]{2}{*}{$\begin{array}{l}\text { No Peroneal } \\
\text { Neuropathy } \\
\quad(n=33)\end{array}$} & \multicolumn{2}{|c|}{$\begin{array}{l}\text { Subclinical Peroneal } \\
\text { Neuropathy }(n=67)\end{array}$} & \multirow[b]{2}{*}{$\begin{array}{c}P \\
\text { Value }\end{array}$} \\
\hline & & $\begin{array}{l}1 \text { Positive } \\
\text { Finding } \\
(n=36)\end{array}$ & $\begin{array}{l}\geq 2 \text { Positive } \\
\text { Findings } \\
(n=31)\end{array}$ & \\
\hline Age, median (IQR), y & $50(37-64)$ & $57(50-64)$ & $60(50-63)$ & .30 \\
\hline Female, No. \% & $18(55)$ & $22(61)$ & $19(61)$ & .82 \\
\hline $\begin{array}{l}\text { Vertigo, dizziness, balance } \\
\text { disorder, No. \% }\end{array}$ & $15(45)$ & $13(36)$ & $25(81)^{a}$ & .01 \\
\hline Impaired vision, No. \% & $7(21)$ & $7(19)$ & $10(32)$ & .43 \\
\hline Osteoarthritis, No. \% & $6(18)$ & $14(39)$ & $14(45.2)$ & .06 \\
\hline Stroke, No. \% & $5(15)$ & $7(19)$ & $5(16)$ & .88 \\
\hline $\begin{array}{l}\text { Recent significant weight loss, } \\
\text { No. } \%\end{array}$ & $6(18)$ & $11(30)$ & $6(19)$ & .40 \\
\hline Diabetes, No. \% & $8(24)$ & $10(28)$ & $13(42)$ & .20 \\
\hline Peripheral neuropathy, No. \% & $13(39)$ & $13(36)$ & $19(61)$ & .09 \\
\hline Heart disease, No. \% & $9(27)$ & $9(25)$ & $12(39)$ & .44 \\
\hline Prior leg surgery, No. \% & $3(9)$ & $11(31)$ & $7(23)$ & .09 \\
\hline Prior low back surgery, No. \% & $1(3)$ & $5(14)$ & $5(16)$ & .19 \\
\hline $\begin{array}{l}\text { Johns Hopkins Fall Risk score, } \\
\text { median (IQR) }\end{array}$ & $6(6-9)$ & $8(6-11)$ & $9(7-11)^{b}$ & .02 \\
\hline \multicolumn{5}{|c|}{$\begin{array}{l}\text { Note: } \chi^{2} \text { or Kruskal-Wallis } \mathrm{H} \text {, and Wilcoxan rank sum post-hoc used as appropriate. } \\
\text { a Ranging from } 0 \text { to } 35 \text {, where a score of }<6=\text { low risk, } 6 \text { to } 13=\text { moderate risk, and }>13=\text { high risk. } \\
\text { b Significant difference from no peroneal neuropathy. }\end{array}$} \\
\hline
\end{tabular}

tory were significantly correlated $\left(\chi^{2}{ }_{1}=6.3014, P<.01\right)$ and the ABC Scale score successfully predicted $63 \%$ of patients who had not fallen and $63 \%$ of patients who had fallen.

\section{Association of SCPN With Falling}

Patients with SCPN (2 or more findings on physical examination) were significantly more likely to selfreport having fallen in the past year in a univariate logistic model $(\mathrm{OR}=3.17$; 95\% CI, 1.14-8.81) (Table 2). After accounting for confounders, patients with SCPN were 4.70 times (95\% CI, 1.39-15.90) more likely to have a self-reported falling the past year (Table 3 ). Patients with only 1 finding of SCPN were at 2.85 times (95\% CI, 0.97-8.38) more likely to report having fallen $(P=.058)$. These finding suggest that as the number of findings for SCPN increases, the association with falls becomes stronger.

\section{Association of SCPN With Perceived Fall Risk}

Patients with SCPN were significantly more likely to have an ABC Scale score of less than 67.0 and thus be at elevated perceived risk for falling in their day-to-day lives in a univariate logistic model $(\mathrm{OR}=4.0$; 95\% CI, 1.40-11.42) (Table 2). After controlling for confounders within a multivariate model, the association of examination findings of SCPN remained similar to univariate associations, though only marginally significant (Table 4).

\section{DISCUSSION}

This cross-sectional analysis identified SCPN in 31\% of hospitalized medical patients. Patients with this often unrecognized disorder were

Table 2. Univariate Associations of Subclinical Peroneal Neuropathy and Falling or High Fall Risk (ABC Score <67.0)

\begin{tabular}{|c|c|c|c|c|c|c|}
\hline Examination Finding & $\begin{array}{c}\text { Fall } \\
\beta \text { Coefficient }\end{array}$ & $\begin{array}{c}\text { Fall } \\
\text { OR }(95 \% \mathrm{Cl})^{\mathrm{a}}\end{array}$ & $P$ Value & $\begin{array}{c}\text { ABC }<67.0 \\
\beta \text { Coefficient }\end{array}$ & $\begin{array}{c}A B C<67.0 \\
\text { OR }(95 \% C l)^{a}\end{array}$ & $P$ Value \\
\hline Normal findings (reference) & $\cdots$ & 1 & .08 & $\ldots$ & 1 & .04 \\
\hline 1 Positive finding & 0.693 & $2.00(0.75-5.30)$ & .16 & 0.693 & $2.00(0.75-5.30)$ & .16 \\
\hline$\geq 2$ Positive findings & 1.153 & $3.17(1.14-8.81)^{b}$ & .03 & 1.389 & $4.00(1.40-11.42)^{b}$ & .01 \\
\hline
\end{tabular}


more likely to have at least 1 self-reported fall in the past year and to have a higher fall risk on the ABC Scale. ${ }^{15}$ This study is the first to describe the prevalence of SCPN and its association with falling.

Numerous factors associated with hospitalization cause or exacerbate compression neuropathies ${ }^{9,23-27}$ : critical illness, weight loss, poorly controlled blood glucose, direct pressure on the nerve at the fibular head while in bed, and prolonged supine positioning with knee extension and ankle plantar flexion. We therefore expect that acute illness and hospitalization in this population exacerbates underlying peroneal nerve compression causing SCPN. Hospitalized or institutionalized patients are at 3 times higher risk of falling than their community-dwelling peers, ${ }^{28,29}$ and the risk of falling is further increased as the number of risk factors associated with multimorbidity, eg, diabetes, increases. ${ }^{30}$ As a result, the high prevalence of SCPN and falling found in this study are not surprising.

Increasing age has not consistently been shown to be a risk factor for inpatient falling, though it is a strong predictor of falls in the community (falls reported by patients in this study occurred predominantly in community settings), fall-related injury, and long-term admission. ${ }^{3,30}$ Most studies of fall risk focus on patients aged 65 years and older, despite falls representing the most common cause of accidental injury in almost every agegroup in the United States. ${ }^{31}$ In our study, the median age of patients increased as the number of examination findings that were positive for SCPN increased, suggesting that the prevalence of SCPN may increase with age. We excluded patients aged 70 years and older to avoid making a false association in an elderly population that has high prevalences of both SCPN and falling, though they may be completely coincidental. The intent of our study was to maximize the number of ambulatory, community-dwelling patients and minimize the number of patients with multimorbidity and polypharmacy who are expected to fall for other reasons. We therefore describe a previously unrecognized risk factor for falling in a slightly younger group of patients (median age 57 years) than most fall studies, although the median age is similar to the reported mean age for inpatient falls of 62 years. ${ }^{32,33}$

Overt peroneal neuropathy, exhibiting classic steppage gait, is an obvious disorder that requires management with a brace or surgery. ${ }^{7}$

When caused by compression at the fibular head, peroneal neuropathy usually follows an insidious course similar to other compression neuropathies (eg, carpal tunnel syndrome). 4,7,8,11,23,34-36 Pain and numbness are less prominent with SCPN. ${ }^{7}$ Symptoms of nerve compression on a physical examination, including a positive Tinel sign, are often found in subclinical disease and are easily reproduced in any clinical setting. $8,16,25,37$ Weakness of dorsiflexion, however, may be subtle and

Table 3. Association of Subclinical Peroneal Neuropathy With Falling Within a Multivariable Model

\begin{tabular}{|c|c|c|c|}
\hline $\begin{array}{l}\text { History and Physical } \\
\text { Examination }\end{array}$ & $\underset{\text { Coefficient }}{\beta}$ & $\begin{array}{c}\text { Fall } \\
\text { OR }(95 \% \mathrm{Cl})^{\mathrm{a}}\end{array}$ & $\begin{array}{c}P \\
\text { Value }\end{array}$ \\
\hline $\begin{array}{l}\text { Normal findings on examina- } \\
\text { tion (reference) }\end{array}$ & $\ldots$ & 1 & .03 \\
\hline 1 Positive finding & 1.046 & $2.85(0.97-8.38)$ & .06 \\
\hline$\geq 2$ Positive findings & 1.547 & $4.70(1.39-15.90)^{b}$ & .01 \\
\hline Osteoarthritis & -0.795 & $0.45(0.18-1.16]$ & .10 \\
\hline Age $>57 y$ & -0.667 & $0.51(0.21-1.29)$ & .15 \\
\hline $\begin{array}{l}\text { Vertigo, dizziness, or balance } \\
\text { disorder }\end{array}$ & 0.365 & $1.44(0.57-3.67)$ & .44 \\
\hline Stroke & 1.346 & $3.84(1.10-13.47)^{b}$ & .04 \\
\hline Recent significant weight loss & -0.879 & $0.42(0.14-1.21)$ & .42 \\
\hline Constantc & -0.591 & $\cdots$ & .23 \\
\hline \multicolumn{4}{|l|}{$\mathrm{OR}=$ odds ratio. } \\
\hline \multicolumn{4}{|c|}{ Note: Nagelkerke $R^{2}=0.215$; overall model significance was $P=.014$} \\
\hline \multicolumn{4}{|c|}{$\begin{array}{l}\text { Associations derived from multivariate logistic regression. Effects of diabetes, poor vision } \\
\text { or blindness, peripheral neuropathy, and global weakness were examined and not found to } \\
\text { confound the association of subclinical peroneal neuropathy and falling. }\end{array}$} \\
\hline \multicolumn{4}{|c|}{ b Denotes statistical significance $(P<.05)$. } \\
\hline c Intercept term of regression equat & & & \\
\hline
\end{tabular}

Table 4. Association of Subclinical Peroneal Neuropathy and Elevated Fall Risk (ABC Score <67.0) Within a Multivariable Model

\begin{tabular}{|c|c|c|c|}
\hline $\begin{array}{l}\text { History and Physical } \\
\text { Examination }\end{array}$ & $\begin{array}{c}\beta \\
\text { Coefficient }\end{array}$ & OR $(95 \% \mathrm{Cl})^{\mathrm{a}}$ & $\begin{array}{c}P \\
\text { Value }\end{array}$ \\
\hline $\begin{array}{l}\text { Normal findings on examina- } \\
\text { tion (reference) }\end{array}$ & & 1 & .22 \\
\hline 1 Positive finding & 0.885 & $2.42(0.77-7.66)$ & .13 \\
\hline$\geq 2$ Positive findings & 0.952 & $2.60(0.74-9.04)$ & .14 \\
\hline Global weakness & 1.060 & $2.89(0.99-8.42)$ & .05 \\
\hline $\begin{array}{l}\text { Vertigo, dizziness, or balance } \\
\text { disorder }\end{array}$ & 0.991 & $2.69(0.98-7.43)$ & .06 \\
\hline Osteoarthritis & -0.756 & $0.47(0.17-1.31)$ & .15 \\
\hline Peripheral neuropathy & 0.874 & $2.40(0.92-6.26)$ & .08 \\
\hline Recent significant weight loss & -0.786 & $0.46(0.15-1.38)$ & .17 \\
\hline Constant ${ }^{\mathrm{b}}$ & -1.490 & $\ldots$ & .01 \\
\hline \multicolumn{4}{|c|}{$\mathrm{ABC}=$ Activities-specific Balance Confidence; $\mathrm{OR}=$ odds ratio. } \\
\hline \multicolumn{4}{|c|}{ Note: Nagelkerke $R^{2}=0.270$; overall model significance was $P=.003$. } \\
\hline \multicolumn{4}{|c|}{$\begin{array}{l}\text { a Associations derived from multivariate logistic regression. The effects of age, diabetes, and } \\
\text { poor vision or blindness were examined and not found to confound this association. } \\
\text { b Intercept term of regression equation. }\end{array}$} \\
\hline
\end{tabular}


not detected with standard strength testing. Unless trained to look for specific signs of peroneal neuropathy, physicians, nurses, and physical therapists are likely to miss the subtle signs of SCPN.

Several studies and meta-analyses have shown that multicomponent programs to prevent falls can reduce the relative risk for falls by up to $30 \%{ }^{2,38-42}$ Slipping, tripping, or stumbling is the most common cause of inpatient and community falls, and gait and balance disorders are the most common cause in long-term care facilities. ${ }^{3,28}$ Even so, no tools that assess risk of falling specifically assess for SCPN, which is hypothesized to give a subtle gait disorder. The Tinetti Gait \& Balance Assessment is the only tool to directly assess overt peroneal neuropathy ${ }^{43}$ Inpatient fall assessment tools do not assess peroneal neuropathy, nor do they rely on gait assessment alone to indirectly assess peroneal neuropathy; thus they will miss SCPN (Table 5). ${ }^{12,44-51}$

New recommendations from the United States Preventative Services Task Force recommend outpatient physical therapy programs to prevent falls in community-dwelling adults. ${ }^{52,53}$ Current physical therapy programs address several impairments that contribute to increased fall risk. ${ }^{54,55}$ No guidelines, however, direct what interventions should be provided when strength or balance deficits are due to SCPN. In this situation, without addressing the compression neuropathy, physical therapy is unlikely to improve peroneal nerve function. Furthermore, in patients with unrecognized SCPN, these programs may increase their confidence and expose them to more risky situations as they increase ambulation. ${ }^{56}$ Primary care physicians are ideally situated to manage this disorder,

Table 5. Peroneal Neuropathy Assessment in Validated Inpatient Fall Risk Assessment Tools

\begin{tabular}{|c|c|c|c|}
\hline Tool & $\begin{array}{l}\text { Assessed } \\
\text { Peroneal } \\
\text { Nerve }\end{array}$ & $\begin{array}{l}\text { How Peroneal } \\
\text { Neuropathy } \\
\text { Assessed }\end{array}$ & Other Factors Assessed \\
\hline Berg balance 45 & No & NA & Balance, transfers, strength \\
\hline Conley Scale ${ }^{46}$ & Indirectly & Gait & History, cognition, vertigo, toileting \\
\hline $\begin{array}{l}\text { Johns Hopkins Fall Risk } \\
\text { Assessment Tool }\end{array}$ & Indirectly & Gait & $\begin{array}{l}\text { Age, fall history, toileting, obsta- } \\
\text { cles, cognition }\end{array}$ \\
\hline Downton index ${ }^{47}$ & Indirectly & $\begin{array}{l}\text { Gait, sensory } \\
\text { examination }\end{array}$ & History, medications, cognition \\
\hline Elderly Mobility Scale ${ }^{48}$ & Indirectly & Gait & Transfers, balance \\
\hline $\begin{array}{l}\text { Schmid Fall Risk } \\
\text { Assessment }{ }^{49}\end{array}$ & Indirectly & Gait & $\begin{array}{l}\text { Mobility, cognition, incontinence, } \\
\text { prior fall history, medications }\end{array}$ \\
\hline STRATIFY50,51 & Indirectly & Gait & $\begin{array}{l}\text { Fall history, agitation, vision, toilet- } \\
\text { ing, footwear, orthostatic sup- } \\
\text { ports, medications, environment }\end{array}$ \\
\hline \multicolumn{4}{|c|}{ NA = not assessed; STRATIFY = St Thomas Risk Assessment Tool in Falling elderly inpatients. } \\
\hline \multicolumn{4}{|c|}{$\begin{array}{l}\text { Note: Among } 7 \text { inpatient fall risk assessment tools commonly used, no assessment tool directly assesses the pero- } \\
\text { neal nerve. Tools that assess gait are likely to miss subclinical peroneal neuropathy, which does not produce the } \\
\text { characteristic steppage gait of overt peroneal neuropathy. }\end{array}$} \\
\hline
\end{tabular}

which may first be recognized in the hospital but may place patients at risk following discharge.

In a hospital setting, several conservative measures can decrease the incidence of SCPN. Careful attention to physiologic parameters associated with compression neuropathy may prevent or ameliorate peroneal neuropathy, such as tight control of blood glucose, thyroid hormone replacement, and avoidance of edema in the lower extremities. ${ }^{4,7,23,57,58}$ Physical therapists and nurses can assist in preventing peroneal neuropathy by implementing positioning programs that avoid pressure on the lateral aspect of the knee and minimizing prolonged periods of knee extension or ankle plantar flexion. Early and frequent mobilization also helps.

After hospitalization, patients should be reexamined for SCPN. Most patients with an acute exacerbation of SCPN will resolve spontaneously. ${ }^{59}$ Patients with persistent symptoms or overt peroneal neuropathy with a steppage gait, however, may warrant peroneal nerve release. ${ }^{11,36}$ Most importantly, identifying SCPN in hospitalized or recently hospitalized patients affords physicians an opportunity to discuss fall risk and prevention with their patients, and minimize obstacles in the hospital room and home that could lead patients to trip and fall.

Our study has a few limitations. The crosssectional design does not allow discernment of a cause-and-effect relationship between SCPN and falling. We excluded patients older than 70 years, making its results difficult to apply to an elderly population at high risk for falling. Our study also relied on a clinical diagnosis of SCPN and patient-reported histories of falling. Peroneal neuropathy can result from injury of the peroneal nerve at any point along its course, not exclusively the fibular head. ${ }^{60}$ Weakness of muscles innervated by the peroneal nerve is not specific for entrapment. For this reason, SCPN was defined as having 2 or more positive findings on examination, and at least 1 finding specific to the fibular head. The sensitivity and specificity of pain at the fibular head have not been studied. The Tinel test is highly specific but only moderately sensitive for entrapment neuropathy at the fibular head. ${ }^{8}$ Consequently, some patients with SCPN but only 1 positive physical finding may have been nondifferentially misclassified as not having SCPN, and 
the association with falling may be underestimated. Although potentially more objective than the clinical examination used in this study, electrodiagnostic tests are costly, and would expose patients to potential pain or harm. We did not assess the frequency of falls and therefore cannot differentiate patients who experience one potentially random fall from patients who fall more frequently, indicating underlying illness. Although we did examine the effects of several confounders on falling, our ability to control for potential confounders was limited by the small sample size, and we did not specifically examine polypharmacy as a potential confounder of these results. Furthermore, our study was not designed to determine risk factors for developing SCPN in hospitalized patients, and our analysis cannot address these questions.

Despite these limitations, our findings suggest that SCPN is common among hospitalized patients and is associated with a history of tripping and falling. Our results further suggest that screening for SCPN, implementing preventive measures, and treating the disorder may help reduce fall incidence in hospitalized and recently discharged patients. Future work is needed to establish a cause-and-effect relationship between SCPN and falls, as well as the prevalence of the disorder in other patient populations.

To read or post commentaries in response to this article, see it online at http://www.annfammed.org/content/14/6/526.

Key words: neuropathy, common peroneal; peroneal nerve diseases; peroneal nerve paralysis; falls, accidental; preventive medicine; nerve compression syndromes

Submitted January 30, 2016; submitted, revised, June 2, 2016; accepted June 15, 2016.

Funding support: This work was generously supported by a grant from the Foundation for Barnes-Jewish Hospital and the National Institutes of Health, grant No. UL1 TR000449.

Disclaimer: The Foundation for Barnes-Jewish Hospital and the National Institutes of Health played no role in the design, conduct, or reporting of this study.

Previous presentations: This work was presented at the Plastic Surgery Research Council Meeting; March 7-9, 2014; New York, New York.

Acknowledgments: We would like to thank Dr Jane Garbutt, MB, ChB, and all members of the Mentored Training Program for Clinical Investigation Seminar at Washington University in St Louis for their contributions to the research design and presentation of this report.

STROBE statement: All data are presented in accordance with STROBE guidelines.

\section{References}

1. Brandis S. A collaborative occupational therapy and nursing approach to falls prevention in hospital inpatients. J Qual Clin Pract. 1999;19(4):215-220.
2. Oliver D, Healey F, Haines TP. Preventing falls and fall-related injuries in hospitals. Clin Geriatr Med. 2010;26(4):645-692.

3. Ellis AA, Trent RB. Do the risks and consequences of hospitalized fall injuries among older adults in California vary by type of fall? J Gerontol A Biol Sci Med Sci. 2001;56(11):M686-M692.

4. Bouche P. Compression and entrapment neuropathies. In: Gérard S Christian K, eds. Handbook of Clinical Neurology. Amsterdam, Netherlands: Elsevier; 2013:311-66.

5. Craig A. Entrapment neuropathies of the lower extremity. PM R. 2013;5(5)(Suppl):S31-S40.

6. Neary D, Ochoa J, Gilliatt RW. Sub-clinical entrapment neuropathy in man. J Neurol Sci. 1975;24(3):283-298. Epub19750301.

7. Flanigan RM, DiGiovanni BF. Peripheral nerve entrapments of the lower leg, ankle, and foot. Foot Ankle Clin. 2011;16(2):255-274.

8. Gillenwater J, Cheng J, Mackinnon SE. Evaluation of the scratch collapse test in peroneal nerve compression. Plast Reconstr Surg. 2011; 128(4):933-939.

9. Campbell WW. Essentials of Electrodiagnostic Medicine. New York, NY: Demos Medical Publishing; 2013.

10. Richardson JK, Ashton-Miller JA. Peripheral neuropathy: an oftenoverlooked cause of falls in the elderly. Postgrad Med. 1996;99(6): 161-172. Epub19960601.

11. Humphreys DB, Novak CB, Mackinnon SE. Patient outcome after common peroneal nerve decompression. J Neurosurg. 2007;107(2): 314-318.

12. Powell LE, Myers AM. The Activities-specific Balance Confidence (ABC) Scale. J Gerontol A Biol Sci Med Sci. 1995;50A(1):M28-M34. Epub19950101.

13. Poe SS, Cvach M, Dawson PB, Straus H, Hill EE. The Johns Hopkins Fall Risk Assessment Tool: postimplementation evaluation. J Nurs Care Qual. 2007;22(4):293-298.

14. Hnizdo S, Archuleta RA, Taylor B, Kim SC. Validity and reliability of the modified Johns Hopkins Fall Risk Assessment Tool for elderly patients in home health care. Geriatr Nurs. 2013;34(5):423-427.

15. Kim KS, Kim JA, Choi YK, et al. A comparative study on the validity of fall risk assessment scales in Korean hospitals. [Korean Soc Nurs Sci]. Asian Nurs Res (Korean Soc Nurs Sci). 2011;5(1):28-37.

16. Spicher C, Kohut G, Miauton J. At which stage of sensory recovery can a tingling sign be expected? a review and proposal for standardization and grading. J Hand Ther. 1999;12(4):298-308. Epub20000106.

17. Dellon AL. Tinel or not Tinel. J Hand Surg Euro. 1984;9(2):216.

18. Marx RG, Hudak PL, Bombardier C, Graham B, Goldsmith C, Wright JG. The reliability of physical examination for carpal tunnel syndrome. J Hand Surg Br. 1998;23(4):499-502. Epub19980903.

19. Cheng CJ, Mackinnon-Patterson B, Beck JL, Mackinnon SE. Scratch collapse test for evaluation of carpal and cubital tunnel syndrome. J Hand Surg Am. 2008;33(9):1518-1524.

20. Compston A. Aids to the investigation of peripheral nerve injuries. Medical Research Council: Nerve Injuries Research Committee. His Majesty's Stationery Office: 1942; pp. 48 (iii) and 74 figures and 7 diagrams; with aids to the examination of the peripheral nervous system. By Michael O'Brien for the Guarantors of Brain. Saunders Elsevier: 2010; pp. [8] 64 and 94 Figures. Brain. 2010;133(10):28382844. Epub20101012.

21. Lajoie Y, Gallagher SP. Predicting falls within the elderly community: comparison of postural sway, reaction time, the Berg balance scale and the Activities-specific Balance Confidence (ABC) Scale for comparing fallers and non-fallers. Arch Gerontol Geriatr. 2004;38(1): 11-26. Epub20031106.

22. Maldonado G, Greenland S. Simulation study of confounderselection strategies. Am J Epidemiol. 1993;138(11):923-936.

23. Mackinnon SE. Pathophysiology of nerve compression. Hand Clin. 2002;18(2):231-241. Epub20021010. 
24. Lederman RJ, Breuer AC, Hanson MR, et al. Peripheral nervous system complications of coronary artery bypass graft surgery. Ann Neurol. 1982;12(3):297-301.

25. Dellon AL. The Dellon approach to neurolysis in the neuropathy patient with chronic nerve compression. Handchir Mikrochir Plast Chir. 2008;40(6):351-360.

26. Dellon AL. Treatment of symptomatic diabetic neuropathy by surgical decompression of multiple peripheral nerves. Plast Reconstr Surg. 1992;89(4):689-697, discussion 698-699. Epub19920401.

27. Aszmann OC, Kress KM, Dellon AL. Results of decompression of peripheral nerves in diabetics: a prospective, blinded study. Plast Reconstr Surg. 2000;106(4):816-822. Epub20000928.

28. Rubenstein LZ, Josephson KR, Robbins AS. Falls in the nursing home. Ann Intern Med. 1994;121(6):442-451.

29. Rubenstein LZ, Powers CM, MacLean CH. Quality Indicators for the Management and Prevention of Falls and Mobility Problems in Vulnerable Elders. Ann Intern Med. 2001;135(8_Part_2):686-93.

30. Currie L. Fall and Injury Prevention. In: Hughes RG, ed. Patient Safety and Quality: An Evidence-Based Handbook for Nurses. Rockville, MD: Agency for Healthcare REeearch and Quality (US); 2008.

31. Injury prevention and control: data and statistics (WISQARS). Centers for Disease Control and Prevention. http://www.cdc.gov/injury/ wisqars/. Accessed May 22, 2016.

32. Hitcho EB, Krauss MJ, Birge S, Claiborne Dunagan W, Fischer I, Johnson $S$, et al. Characteristics and circumstances of falls in a hospital setting: a prospective analysis. J Gen Intern Med. 2004;19(7): 732-9. Epub 2004/06/24.

33. Fischer ID, Krauss MJ, Dunagan WC, et al. Patterns and predictors of inpatient falls and fall-related injuries in a large academic hospital. Infect Control Hosp Epidemiol. 2005;26(10):822-827.

34. Mackinnon SE, Dellon AL, Hudson AR, Hunter DA. Chronic human nerve compression - a histological assessment. Neuropathol Appl Neurobiol. 1986;12(6):547-565. Epub19861101.

35. Stewart JD. Foot drop: where, why and what to do? Pract Neurol. 2008;8(3):158-169.

36. Mackinnon SE. Nerve Surgery. 1st ed. New York, NY: Thieme; 2014

37. Lee $\mathrm{CH}$, Dellon AL. Prognostic ability of Tinel sign in determining outcome for decompression surgery in diabetic and nondiabetic neuropathy. Ann Plast Surg. 2004;53(6):523-527. Epub20041217.

38. Miake-Lye IM, Hempel S, Ganz DA, Shekelle PG. Inpatient fall prevention programs as a patient safety strategy: a systematic review. Ann Intern Med. 2013;158(5_Part_2):390-6.

39. Cameron ID, Gillespie LD, Robertson MC, et al. Interventions for preventing falls in older people in care facilities and hospitals. Cochrane Database Syst Rev. 2012;12:CD005465.

40. Coussement J, De Paepe L, Schwendimann R, Denhaerynck K, Dejaeger $\mathrm{E}$, Milisen K. Interventions for preventing falls in acute- and chronic-care hospitals: a systematic review and meta-analysis. J Am Geriatr Soc. 2008;56(1):29-36.

41. DiBardino D, Cohen ER, Didwania A. Meta-analysis: multidisciplinary fall prevention strategies in the acute care inpatient population. J Hosp Med. 2012;7(6):497-503. 10.1002/jhm.1917.

42. Jensen J, Lundin-Olsson L, Nyberg L, Gustafson Y. Fall and injury prevention in older people living in residential care facilities. A cluster randomized trial. Ann Intern Med. 2002;136(10):733-741.

43. Tinetti ME, Williams TF, Mayewski R. Fall risk index for elderly patients based on number of chronic disabilities. Am J Med. 1986; 80(3):429-434. Epub19860301.

44. Scott V, Votova K, Scanlan A, Close J. Multifactorial and functional mobility assessment tools for fall risk among older adults in community, home-support, long-term and acute care settings. Age Ageing. 2007;36(2):130-139.
45. Berg KO, Wood-Dauphinee SL, Williams II, Maki B. Measuring balance in the elderly: validation of an instrument. Can J Public Health 1992;83(Suppl 2):S7-S11.

46. Conley D, Schultz AA, Selvin R. The challenge of predicting patients at risk for falling: development of the Conley Scale. Medsurg Nurs. 1999;8(6):348-354

47. Vassallo M, Stockdale R, Sharma JC, Briggs R, Allen S. A comparative study of the use of four fall risk assessment tools on acute medical wards. J Am Geriatr Soc. 2005;53(6):1034-1038.

48. Prosser L, Canby A. Further validation of the Elderly Mobility Scale for measurement of mobility of hospitalized elderly people. Clin Rehabil. 1997;11(4):338-343.

49. Schmid NA. 1989 Federal Nursing Service Award Winner. Reducing patient falls: a research-based comprehensive fall prevention program. Mil Med. 1990;155(5):202-207.

50. Oliver D, Papaioannou A, Giangregorio L, Thabane L, Reizgys K, Foster G. A systematic review and meta-analysis of studies using the STRATIFY tool for prediction of falls in hospital patients: how well does it work? Age Ageing. 2008;37(6):621-627.

51. Oliver D, Britton M, Seed P, Martin FC, Hopper AH. Development and evaluation of evidence based risk assessment tool (STRATIFY) to predict which elderly inpatients will fall: case-control and cohort studies. BMJ. 1997;315(7115):1049-1053.

52. Moyer VA; U.S. Preventive Services Task Force. Prevention of falls in community-dwelling older adults: U.S. Preventive Services Task Force recommendation statement. Ann Intern Med. 2012;157(3) 197-204.

53. Michael YL, Whitlock EP, Lin JS, Fu R, O'Connor EA, Gold R; US Preventive Services Task Force. Primary care-relevant interventions to prevent falling in older adults: a systematic evidence review for the U.S. Preventive Services Task Force. Ann Intern Med. 2010;153(12): 815-825.

54. Clemson L, Fiatarone Singh MA, Bundy A, et al. Integration of balance and strength training into daily life activity to reduce rate of falls in older people (the LiFE study): randomised parallel trial. BMJ. 2012;345:e4547.

55. Halvarsson A, Oddsson L, Olsson E, Farén E, Pettersson A, Ståhle A. Effects of new, individually adjusted, progressive balance group training for elderly people with fear of falling and tend to fall: a randomized controlled trial [published correction appeared in Clin Rehabil. 2012 Nov;26(11):1055]. Clin Rehabil. 2011;25(11):1021-1031.

56. Halvarsson A, Franzén E, Farén E, Olsson E, Oddsson L, Ståhle A Long-term effects of new progressive group balance training for elderly people with increased risk of falling - a randomized controlled trial. Clin Rehabil. 2013;27(5):450-458.

57. Dellon AL, Mackinnon SE, Seiler WA IV. Susceptibility of the diabetic nerve to chronic compression. Ann Plast Surg. 1988;20(2):117119. Epub19880201.

58. Sunderland S. The anatomy and physiology of nerve injury. Muscle Nerve. 1990;13(9):771-784. 10.1002/mus.880130903.

59. Aprile I, Caliandro P, Giannini F, et al; Italian CTS and other entrapments Study Group. Italian multicentre study of peroneal mononeuropathy at the fibular head: study design and preliminary results. Acta Neurochir Suppl. 2005;92:63-68. Epub20050416.

60. Van Langenhove $M$, Pollefliet $A$, Vanderstraeten $G$. A retrospective electrodiagnostic evaluation of footdrop in 303 patients. Electromyogr Clin Neurophysiol. 1989;29(3):145-152. Epub19890401. 